\title{
Medical Services during the XXVII World Summer Universiade 2013 in Kazan
}

\author{
Elena Mikhaylovna Razumovskaya
}

Kazan Federal University , 18 Kremlyovskaya st., Kazan 420008

Timur Sergeevich Mishakin

Kazan Federal University , 18 Kremlyovskaya st., Kazan 420008

Mikhail Leonidovich Popov

Kazan Federal University ,18 Kremlyovskaya st., Kazan 420008

Nadezhda Gennadyevna Kucevol

Kazan Federal University, 18 Kremlyovskaya st., Kazan 420008

Doi:10.5901/mjss.2014.v5n18p17

\section{Abstract}

Public health is the most important factor in economic, political, social and cultural development of the country. Health is a fundamental, essential and socially important value. Health care system plays a substantial role in economic growth. Health care system - is one of the most important key factor in the preparation of any massive international event. The Success of such events largely depends on preparing of the health care system and medical service system. Medical service system is the most important in terms of the international sports events. Singularities of such events are: mass gatherings; the international level of the event; the probability of sports injuries among athletes, the need for athletes training and preparation, the doping control; the probability of emergency situations when a lot of people need medical assistance. Experience of the XXVII World Summer Universiade 2013 in Kazan can be called the most successful and efficient. Preparation of medical service system played one of the main role in success of this event. So it defined the purpose of this article: to analyze experience of the XXVII World Summer Universiade 2013. Accordingly, this study proposes a practical framework methodology to assist construction of the health care system and medical service system in terms of mass international sporting events.

Keywords: Health care system, medical service, mass gatherings, international sporting events.

A (public) health system is regarded by the World Health Organization as consisting of "all organizations, people and actions whose primary intent is to promote, restore or maintain health" (World Health Organization, 2009). This definition is also used by the World Bank and the European Union. The World Health Organization has identified six building blocks characterizing good health systems, which can also serve as orientation for assessing health systems and identifying future challenges (World Health Organization, 2008).

1. Effective, safe and quality service delivery to those that need them, when and where needed and with a minimum waste of resources;

2. A health workforce working in responsive, fair and efficient ways to achieve the best possible health outcomes, given the available resources and circumstances - this requires for instance that there are sufficient competent and productive health workers and that they are fairly distributed;

3. A well-functioning health information system ensuring the production, analysis, dissemination and use of reliable and timely information on health determinants, health system performance, as well as health status supporting management, leadership and governance;

4. Equitable access to essential medical products, vaccines and technologies of assured quality, safety, efficacy and cost-effectiveness;

5. A good and efficient health financing system, providing incentives for providers and users of health services to be efficient while ensuring that people can use health services without facing the risk of impoverishment linked with having to pay for them; 
6. Strategic leadership and governance (stewardship) based on effective oversight, coalition building, regulation, attention to system-design and accountability in order to protect the public interest in health.

It is acknowledged that the healthcare sectors consist of a variety of players, e.g. clinicians, hospitals and other healthcare facilities, insurance companies, purchasers of healthcare services, pharmaceutical and device industries and, with the growing emphasis on self-responsibility, also even the healthy individual (World Health Organization, 2009).

Physicians are increasingly called upon to provide medical support for mass gatherings such as concerts, sporting events, political conventions, and other special events. Until recently, individuals planning such support have had little reliable information to assist them in determining what specific personnel and equipment are necessary to optimally support a mass gathering (Grange, J.T., 2002).

Kazan is the capital of the economically stable and dynamically developing subordinate entity of the Russian Federation - The Republic of Tatarstan. Kazan has 1.2 million citizens. In 2005, the city celebrated the 1000th anniversary of its foundation. The city is inhabited by more than 100 nationalities, people of Christian, Muslim and other faiths, and is famous for it's good neighborliness and tolerance. Large-scale international competitions, which were held in Kazan, showed that the capital of Tatarstan has all the required resources, including human, for organizing such events on a high level.

All this determined the success of Kazan in bidding the right to hold the XXVII World Summer Universiade 2013. On May 31, 2008 The International University Sports Federation (FISU) in Brussels decided to hold the XXVII World Summer Universiade 2013 in Kazan.

Such large-scale events, on the one hand, need all resources to be concentrated, such as: material, organizational, intellectual, and on the other hand, provide a unique opportunity to develop the entire town infrastructure, economy, training, education, culture and student sport (Kadyrov A.R., 2014).

From this historical point of view, the highly symbolic dates associated with Student games 2013 in Kazan are being clarified: the 90th anniversary of the World Student Games in Paris and the 40th anniversary since the VII summer Student games in Moscow (Gafurov I.R., 2014).

The Universiade, often referred to as the World University Games, is an international multi-sport event, organized by the International University Sports Federation (FISU) for university athletes and is important second only to the Olympic Games.

XXVII Summer Universiade in Kazan had 7980 athletes (4 835 men and 3145 women) from 160 countries (Burganov R.T., 2014).

For example, XXIV Summer Universiade 2005 in Bangkok had 9007 participants from 152 countries (Lertwanich, P. et al,. 2011).

The refereeing of the Universiade 2013 provided by 2158 referees, 766 of them had international qualifications. 33 competitive and 16 training facilities were involved during the Universiade 2013, performed competitions in 27 sports, raffled 351 set of medals, 19,970 volunteers were involved in the Universiade.

Medical support of the Universiade 2013 was organized in accordance with the minimum requirements of the International University Sports Federation and the Concept of health, doping and sanitary-epidemiological security of the XXVII World Summer Universiade 2013 in Kazan (Gataullin M.R. et al., 2013).

To work at the University Games were held in 1476 medical workers, including 167 specialists of Federal Medical and Biological Agency, 719 doctors and 757 nurses from hospitals in Tatarstan, 138 mobile teams, 1 aero-medical team worked at the University Games.

To compare with, XXIV Summer Universiade 2005 in Bangkok had only 371 medical workers (Lertwanich, P. et al,. 2011).

The following measures have been implemented in preparing medical support for the Universiade 2013, Kazan:

- Specially created headquarters worked at the Ministry of Health.

- Universiade Village Medical Center was commissioned and equipped;

- The Emergency Hospital was constructed, commissioned and equipped;

- Health centers for athletes and visitors was opened and equipped;

- On-site medical centers for athletes and visitors was opened and equipped;

- 35 health medical posts for spectators and 55 for athletes were deployed on sports facilities

- Mobile medical teams was created;

- 28 ambulances class "B" and 39 class "C" was bought;

- Ambulance crews was provided in accordance with the schedule of events ;

- Medical-evacuation plan, including air medical evacuation, was approved;

- Inspection exercises of medical facilities were held to prevent the proliferation of dangerous infections; 
- Sanitary environment monitoring was carried out in Kazan;

- Laboratory monitoring of air quality, water and soil was carried out during the Universiade;

- Universiade staff and volunteers vaccination was carried out;

- Sanitary and quarantine epidemiology station was created;

- Anti-Doping supporting of the Universiade was carried out.

Seven Universiade Hospitals were provided a 24-hour care system in order to keep medical support for all client groups of the Universiade 2013:

- $\quad$ The Republican Clinical Hospital;

- The Children's Republican Clinical Hospital;

- The Interregional Clinical Diagnostic Center;

- The Republican Clinical Hospital of Infectious Diseases;

- $\quad$ The Emergency Hospital (City Hospital \# 7);

- The Republican Clinical Ophthalmological hospital;

- The Medical Center in the Universiade Village

For example, The Emergency Hospital (City Hospital \# 7), was one of the main hospitals of the Universiade 2013, which provided medical support during opening and closing ceremonies at the Kazan Arena stadium. It included diagnostic department and 12-storey surgical building with a total area of 41.5 thousand meters.

It should be noted that during the Summer Universiade 2005 in Bangkok only two hospitals were involved: The Athletes Village Polyclinic and The Thammasat Hospital (Lertwanich, P. et al,. 2011).

The medical service provided care for 12940 people that had accreditation for Universiade 2013 in Kazan, 3340 of cases were a result of sports injuries and 9600 of them were a result of common diseases, 158 people were hospitalized.

During an international multi-sport competition, the medical care system is an important part and should be well established. Even though care of the athletes is essential, appropriate medical care should be also available to all involved in the events (Brennan, R.J., 1997).

Medical services during the XXVII World Summer Universiade 2013 were set up for all competition and training venues and also covered the athletes resident and non-competition venues including the official hotels, the press center, and during the opening and closing ceremonies.

A detailed contingency plan for mass casualty scenarios with the inclusion of other hospitals and level-A trauma centers should be present during planning and execution of a major sporting event (Milne, C., et al, 1999). Due to possible additional threats, emergent particularly during the last few years, an inclusion of emergency services and law enforcement in contingency planning should be considered to address the threat of terror attacks (Keim, M.E. and D. Williams, 1997)

Providing medical care in the mass gathering sport events is a big challenge for the medical teams. This report provides information on medical organization and overall medical care provided during the XXVII World Summer Universiade 2013.

This information might be useful for planning medical services in international multi-sport competitions in the future.

\section{References}

Brennan, R.J., 1997. Medical and public health services at the 1996 Atlanta Olympic Games: an overview.. Med J Aust, pp: 595-598.

Bagautdinova, N.G., Eshugova, S.K., Saipullaev, U., Karasik, E.A. Methods of technology commercialization in projects of the agrofood system (AFS) development // World Applied Sciences Journal, 27(13), 2013, 48-52.

Delaney, J.S., 2002. Mass casualties and triage at a sporting event.. Br J Sports Med, pp: 85-88.

Fakhrutdinova, E., Kolesnikova, J., Kiselkina, O., Khalikov, A. Issues of commercialization of intangible property rights in Russia// World Applied Sciences Journal. Volume 27, Issue 13, 2013, Pages 72-76.

Maksutina E.V., Makarov A.N., Nazmeev E.F., Alpatova E.S. Assessment of economic efficiency of investments into the human capital in modern conditions. Life Science Journal 2014; 11 (6s): 376-379.

Bagautdinova B.G., Sarkin A.V, Khadiullina G.N., Averyanov B.A., Arzhantseva N. Development of Paternalistic Strategy of Industrial Growth with Regard to Institutional Traps (Qwerty- Effects)// Mediterranean Journal of Social Sciences.- Vol.5, No12, (2014)pp.49-54.

Bagautdinova N.G., Safiullin L.N., Minnahmetov R.R. Institutionalization of Firm Environment in Conditions of Growing Turbulence/l Mediterranean Journal of Social Sciences.- Vol.5, No12, (2014)-pp.55-58.

Grange, J.T., 2002. Planning for large events. Curr Sports Med Rep. Curr Sports Med Rep, pp: 156-161.

Lertwanich, P. et al., 2011. Medical Services during the 24th Summer Universiade. Siriraj Med, pp: 8-11.

Milne, C., M. Shaw and J. Steinweg, 1999. Medical issues relating to the Sydney Olympic Games. Sports Medicine, 28: 287-298.

Primary health care, including health system strengthening // World Health Organization URL: http://www.who.int/gb/ebwha/pdf_files/ 
EB124/B124_8-en.pdf (Accessed on April 7, 2014)

Strengthening Health Systems to Improve Health Outcomes // World Health Organization URL: http://www.who.int/healthsystems /strategy/everybodys_business.pdf (Accessed on April 7, 2014)

Melnik, A.N. Problems and prospects of the formation of clusters in the power engineering / A.N. Melnik, A.R. Sadriev // World Applied Sciences Journal. - 2013. - v. 25

Isaeva, T.N., Safiullin, L.N., Bagautdinova, N.G., Shaidullin, R.N. Aspects of a multi-level study of competitive performance of objects and subjects of economic management // World Applied Sciences Journal, 27(13), 2013, 116-119.

Bagautdinova N.G, Safiullin L.N, Badrtdinov N.N The Role of Consumer Expenses in Ensuring Forward Dynamics of The Russian Economy/l Mediterranean Journal of Social Sciences.- Vol.5, No12, (2014)-pp.43-48.

Askhatova L.I., Bulnina I.S. Quality-of-life (QOL) improvement as a strategic resource of sustainable social and economic development of a region. Life Science Journal 2014 ; 11(6s): 354-357.

Safiullin, M.R., Eflova M.U., Nagimova A.M. (2012). Social well-being and self-identification of the middle class in the Republic of Tatarstan. Sociologicheskie issledovaniya, 9, 28-32.

Ajupov A.A. The Design and Use of Swap-Contracts in the Financial Markets // World Applied Sciences Journal, 27(13), 2013, pp. 1-4.

FISU today // International University Sport Federation URL: http://www.fisu.net/en/FISU-today-3417.html (Accessed on April 7, 2014).

Novenkova A.Z., Gafurov I.R., Kalenskaya N.V. Marketing of Educational Services: Research on Service Providers Satisfaction /I Procedia Economics and Finance, Volume 5, 2013, Pages 368-376.

Safiullin, M.R., Safiullin, N.Z., Saipullaev, U.A., Safiullin, L.N. (2013) Estimation of competitiveness of russian regions by economic activity // Middle East Journal of Scientific Research 16 (10) PP. 1413 - 1418. doi: 10.5829/idosi.mejsr.2013.16.10.12066 